\title{
An Audit of Cesarean Section in Obstetric Department at Benha Educational Hospital Mohamed Abdelwahab Seid Ahmed
}

Department of Obstetrics and Gynecology, Benha Educational Hospital,

Met-Ghamr City, Eldaqahlia Governorate, Egypt

Mobile: 01068730406; Email: Elnaggar662003@yahoo.com

\begin{abstract}
The aim of the study is to make an audit for all females delivered by cesarean section (CS) at the Department of Obstetrics and Gynecology at Benha Educational Hospital for 6 months, so as to improve the quality of care and perform continuous quality improvement. Our study concluded that cesarean section was performed for women of different ages commonly between $18-45$ years. The most common indication of cesarean section was previous cesarean section. Postoperative stay was mainly between 1 to 4 days. The resident doctors were the main surgical staff who performed cesarean section and spinal anesthesia was the most common method of anesthesia used.
\end{abstract}

Keywords: Audit, Cesarean section, Benha Hospital.

\section{INTRODUCTION}

There has been a marked increase in the number of cesarean sections in many countries during the last years ${ }^{(\mathbf{1 - 3})}$ for example, cesarean sections are now performed in over 22 percent of all births in Great Britain ${ }^{(4)}$, and in 30 percent of all births in the USA ${ }^{(5,6)}$. Cesarean section is the common surgical procedure done for women in the USA ${ }^{(\mathbf{5 ,})}$. With this increase in the number of cesarean sections, the cost of maternity care was increased. ${ }^{(7)}$

It was claimed that the cesarean section rate is too high, and that future increase in the rate should be limited, for economic and medical reasons. For example, in the WHO guidelines, it is recommended that the cesarean section rate should not be more than 10-15 percent in any country ${ }^{(8)}$. This is supported by studies that show an increased risk of adverse side effects with cesarean section, particularly if the medical indications are weak (9). Examples of complications after cesarean section are hemorrhage, infection, and thrombosis, and women have an increased risk of complications in subsequent pregnancies (such as uterine rupture and placenta previa) (10-12).

Cesarean section rate in Egypt increased from $15.3 \%$ in 1992 to $18.5 \%$ in 1995 to a high of $20.9 \%$ in 2000. Dis-aggregation by type of hospital (public or private) showed a rising trend of cesarean section in both private and public birth ${ }^{(13)}$.

\section{AIM OF THE WORK}

The study was aimed to audit the management of cesarean section in Benha Educational Hospital so as to improve the quality of patient care and outcome and to drive continuous quality improvement.

\section{SUBJECTS AMD METHODS}

This study was conducted at the Department of Obstetrics and Gynecology, in Benha Educational Hospital and carried out on all pregnant women giving birth by CS within 6 months from June 2018 till November 2018. This study included 1500 females that gave birth, 979 (65.3\%) delivered by CS, 521 (34.7) delivered by vaginal delivery. This study is a cross sectional prospective study. The data was completed from the data sheet that was prepared for every female who attended Benha Educational Hospital for cesarean section.

The study was approved by the Ethics Board of Benha Educational Hospital and an informed written consent was taken from each participant in the study.

The data sheets were checked for the followings data as: [Full history taking, Thorough clinical examination (General- Abdominal- Local), Investigations as: (Preoperative investigations $\{\mathrm{CBC}, \mathrm{ABO}, \mathrm{Rh}$, Urine analysis, Fasting blood sugar, PT, PTT, INR,ALT,AST, Urea, Creatinine\}, Ultrasonography to assess the followings: \{Gestational age (preterm- full-term- post-term), placental site (fundal posterior- fundal anterior-placenta previa marginalis), Liquor Amnii (adequate polyhydramnios -oligohydramnios) and Biophysical profile\}, The different indications reported in the data sheet were summarized in the following factors:\{Previous cesarean section, Absolute Indications and Relative Indications which includes: (breech presentation, face presentation, shoulder presentation, Antepartum hemorrhage. Maternal causes (preeclampsia, eclampsia, DM and others), failed induction, failed progress, postdate, obstructed labour, Assisted reproductive technique (ART), Amniotic fluid causes (PROM, drained liquor, Severe oligohydramnios) and twins, preoperative preparations (Antibiotic - showering), Sterilization of skin, Fixation of urinary catheterization or not, Type of anesthesia either: spinal or general, Surgeon who performed the operation either resident, assistant specialist or specialist, Type of uterine incision either LSCS or USCS, Intraoperative 
complications as uterine artery injury, bleeding, broad ligament hematoma, massive adhesions, bladder injury, intestine injury, Who deals with complications? and how?, Time taken for cesarean section from induction of anesthesia to skin closure, Postoperative care, complications as $1^{\text {ry }}$ postpartum hemorrhage, $2^{\text {ry }}$ postpartum hemorrhage, fever and wound infection, Postoperative Antibiotic, Time of removal of urinary catheter and Time of discharge, Maternal morbidity and ICU admission and Neonatal outcome as (Primary neonatal outcome were recorded in the form of Heart rate, Respiratory rate, 1 minute and 5-minute Apgar score, neonatal complications as (Respiratory distress Meconium aspiration, Neonatal sepsis, Neonatal jaundice, Neonatal intensive care unit admission), Blood gases done or not.)].

Privacy of all women data is granted and there will be code number for every woman file that includes all data and informed consent had obtained from all women.

\section{Statistical Analysis}

The statistical analysis of data was done by using excel program (Microsoft office 2013) and SPSS (statistical package for social science) program (SPSS, Inc, Chicago, IL) version 20. Kolmogorov-Smirnov test was done to test the normality of data distribution. Qualitative data were presented as frequency and percentage.

Quantitative data were presented as mean and standard deviation or median and range.

\section{RESULTS}

Out of total 1500 females that gave birth, 979 (65.3\%) delivered by CS. According to age distribution the study included 979 females; their age ranged from 18 to 45 years with a mean of $28.8 \pm 4.9$ years. The majority of cases were in their third decade $(53.3 \%)$ followed by fourth decade $(40.5 \%)$, then second decade $(3.4 \%)$ and finally fifth decade $(2.7 \%)$. [Table (1)].

Table (1): Mode of delivery and range of age in studied cases.

\begin{tabular}{|c|c|c|c|}
\hline Mode & $\mathbf{N}$ & $\%$ & $\begin{array}{c}\text { Age Range } \\
\text { (ys.) }\end{array}$ \\
\hline Vaginal delivery & 521 & 34.7 & $18-42$ \\
\hline $\mathrm{CS}$ & 979 & 65.3 & $18-45$ \\
\hline Total & 1500 & 100 & \\
\hline
\end{tabular}

According to indication(s) for CS: Relative indications were $27.6 \%$, absolute indications were $10.8 \%$ and the most common was previous CS was $61.6 \%$ [Table (2)].
Table (2): Indications of CS in studied cases.

\begin{tabular}{|l|l|c|c|}
\hline \multicolumn{2}{|c|}{} & N & \% \\
\hline Absolute & Total & 106 & 10.8 \\
\hline \multirow{4}{*}{ Relative } & Mechanical causes & 270 & 27.6 \\
\cline { 2 - 4 } & Medical causes & 53 & 5.4 \\
\cline { 2 - 4 } & Infertility causes & 7 & 23 \\
\cline { 2 - 4 } & Other Obstetrics causes & 187 & 19.1 \\
\hline \multirow{3}{*}{$\begin{array}{l}\text { Previous } \\
\text { CS }\end{array}$} & Total & 603 & 61.6 \\
\cline { 2 - 4 } & previous 1 & 265 & 27.1 \\
\cline { 2 - 4 } & More than previous 1 & 338 & 34.5 \\
\hline Total & & 979 & 100 \\
\hline
\end{tabular}

According to ultrasound findings; gestational ages in most of cases were full term (92.3\%), while post term were $(4.1 \%)$, placenta site in most of cases were fundo posterior (67.4\%) and placenta previa were only 9 cases, amount of liquor in most of cases were adequate amount of liquor $(93.7 \%)$, while polyhydramnios represent (0.9) and oligohydramnios were (5.4\%). Biophysical profile No. of cases with biophysical profile $\geq 8$ were 879 , while No. of cases with biophysical profile $<8$ were 100 . [Table (3)].

Table (3): Gestational age and ultrasound findings in studied cases.

\begin{tabular}{|c|c|c|c|}
\hline & & $\mathbf{N}$ & $\%$ \\
\hline \multirow{3}{*}{$\begin{array}{l}\text { Gestational } \\
\text { Age }\end{array}$} & $\begin{array}{l}\text { Preterm }(<37 \\
\text { weeks })\end{array}$ & 35 & 3.6 \\
\hline & $\begin{array}{l}\text { Full-term }(37-42 \\
\text { weeks })\end{array}$ & 904 & 92.3 \\
\hline & $\begin{array}{l}\text { Post term }(>42 \\
\text { weeks })\end{array}$ & 40 & 4.1 \\
\hline \multirow{3}{*}{ Placenta site } & Fundo posterior & 660 & 67.4 \\
\hline & Fundo anterior & 310 & 31.7 \\
\hline & $\begin{array}{l}\text { Placenta previa } \\
\text { marginalis }\end{array}$ & 9 & 0.9 \\
\hline \multirow{3}{*}{ Liquor } & Adequate & 917 & 93.7 \\
\hline & Polyhydramnios & 9 & 0.9 \\
\hline & Oligohydramnios & 53 & 5.4 \\
\hline \multirow{2}{*}{$\begin{array}{l}\text { Biophysical } \\
\text { profile }\end{array}$} & $<8$ & 100 & 10.2 \\
\hline & $\geq 8$ & 879 & 89.8 \\
\hline
\end{tabular}

According to laboratory investigations: $\mathrm{CBC}$ was done for $96.5 \%$ of cases, ABO-RH done for $96.5 \%$, PT, INR, APTT done for $53.5 \%$, and urine analysis done for 19.4\%. [Table (4)]. 
Table (4): Laboratory investigations of studied cases.

\begin{tabular}{|l|c|c|}
\hline & $\mathbf{N}$ & $\mathbf{\%}$ \\
\hline CBC & 945 & 96.5 \\
\hline ABO-RH & 945 & 96.5 \\
\hline PT, INR, APTT & 524 & 53.5 \\
\hline Urine analysis & 190 & 19.4 \\
\hline Fasting blood sugar & 37 & 3.8 \\
\hline ALT & 37 & 3.8 \\
\hline AST & 37 & 3.8 \\
\hline Urea & 37 & 3.8 \\
\hline Creatinine & 37 & 3.8 \\
\hline Full investigations & 37 & 3.8 \\
\hline
\end{tabular}

According to antibiotic use all studied females received antibiotic before and after C.S and shower was not practiced for any cases, all females were catheterized. Catheters were removed after mean time of 3.5 hours, ranged from 2 to 20 hours but there was one case with bladder injury in which catheter remained for 14 days. As regard to type of anesthesia, it was spinal in $93.3 \%$ of cases, general in $5.1 \%$ and $1.6 \%$ received both types of anesthesia [Table (5)].

Table (5): Type of anesthesia used with studied cases.

\begin{tabular}{|l|c|c|}
\hline Anesthesia & N & \% \\
\hline Spinal & 913 & 93.3 \\
\hline General & 50 & 5.1 \\
\hline Spinal and general & 16 & 1.6 \\
\hline Total & 979 & 100 \\
\hline
\end{tabular}

In $91 \%$ of cases the resident doctor was the surgeon. While $6.5 \%$ of cases were performed by the assistant specialist, and the remaining $2.5 \%$ of cases were managed by the specialist. [Table (6)].

Table (6): Doctors whom managed the cesarean sections.

\begin{tabular}{|l|c|c|}
\hline Surgeon & N & \% \\
\hline Resident & 891 & 91 \\
\hline Assistant specialist & 64 & 6.5 \\
\hline Specialist & 24 & 2.5 \\
\hline Total & 979 & 100 \\
\hline
\end{tabular}

All done cesarean sections were lower uterine segment incision (L.S.C.S), $80.8 \%$ of cases had no complications, the \% of residents who shared in complications was $97 \%$, while the assistant specialist shared in complications in $3 \%$ and the specialist were the one who managed these complications [Table (7)].
Table (7): Percentage of occurrence of intraoperative complications in studied cases.

\begin{tabular}{|l|c|c|}
\hline & $\mathbf{N}$ & $\mathbf{\%}$ \\
\hline No intraoperative complications & 791 & 80.8 \\
\hline With intraoperative Complications & 188 & 19.2 \\
\hline
\end{tabular}

Intraoperative complications occurred in 188 (19.2\%) of all studied females, from those uterine artery injury was the most common complication $(9.7 \%)$, then atonic bleeding in $8.7 \%$. Other intraoperative complications are shown in [Table (8)].

Table (8): Intraoperative complications that occurred to studied cases.

\begin{tabular}{|l|c|c|}
\hline \multicolumn{1}{|c|}{ Intraoperative } & N & $\%$ \\
\hline Uterine artery injury & 95 & 9.7 \\
\hline Atonic bleeding & 85 & 8.7 \\
\hline Massive adhesions & 2 & 0.2 \\
\hline Extension of incision to lower segment & 1 & 0.1 \\
\hline Couvelaire uterus up to hysterectomy & 2 & 0.2 \\
\hline Broad ligament hematoma & 1 & 0.1 \\
\hline Bladder injury & 1 & 0.1 \\
\hline Intestine injury & 1 & 0.1 \\
\hline Total & 188 & 19.2 \\
\hline
\end{tabular}

Postoperative complications occurred in $(10.1 \%)$ of all studied females, from those fever was the most common complication (4.5\%). Other postoperative complications, details of ICU, admission and the mortality rate are shown in [table (9)]

Table (9): Postoperative complications occurred to studied cases.

\begin{tabular}{|l|c|c|c|c|c|c|}
\hline \multirow{2}{*}{ Postoperative } & \multirow{2}{*}{$\mathbf{N}$} & \multirow{2}{*}{$\%$} & \multicolumn{2}{|c|}{$\begin{array}{c}\text { ICU } \\
\text { admission }\end{array}$} & \multicolumn{2}{|c|}{$\begin{array}{c}\text { Mortality } \\
\text { rate }\end{array}$} \\
\cline { 4 - 7 } & & & $\mathbf{N}$ & $\%$ & $\mathbf{N}$ & $\%$ \\
\hline Fever & 44 & 4.5 & 4 & 0.4 & & \\
\hline $\begin{array}{l}\text { Wound } \\
\text { infection }\end{array}$ & 22 & 2.3 & & & & \\
\hline $\begin{array}{l}1^{\text {ry }} \text { postpartum } \\
\text { hemorrhage }\end{array}$ & 16 & 1.6 & 9 & 0.9 & 1 & 0.1 \\
\hline $\begin{array}{l}2^{\text {ry }} \text { postpartum } \\
\text { hemorrhage }\end{array}$ & 13 & 1.3 & 7 & 0.7 & & \\
\hline Paralytic ileus & 3 & 0.3 & 3 & 0.3 & & \\
\hline Eclampsia & 1 & 0.1 & 1 & 0.1 & 1 & 0.1 \\
\hline Total & 99 & 10.1 & 24 & 2.4 & 2 & 0.2 \\
\hline
\end{tabular}

According to time of discharge; the mean time was $24 \mathrm{~h}$. [table (10)]. 
Table (10): Time of discharge after cesarean sections.

\begin{tabular}{|l|l|l|l|}
\hline Discharge after & Mean & SD & Range \\
\hline Total (hours) & 24 & 0.2 & $20-96$ \\
\hline
\end{tabular}

As regard to neonatal outcome, No. of neonates with Apgar score 1 minute <7 were 205 (20.9\%) while No. of neonates with Apgar score 5 minute $<7$ were 172 (17.6\%). Neonatal complications occurred in (19.5\%) from those respiratory distress was the most common complication $(9.2 \%)$ others are shown in [table (11)].

Table (11): Neonatal outcome of studied cases.

\begin{tabular}{|c|c|c|c|}
\hline & $\mathbf{N}$ & $\%$ \\
\hline \multirow{2}{*}{$\begin{array}{l}\text { Fetal heart } \\
\text { rate }\end{array}$} & $<100$ & 70 & 7.2 \\
\hline & $\geq 100$ & 909 & 92.8 \\
\hline \multirow{2}{*}{$\begin{array}{l}\text { Respiratory } \\
\text { rate }\end{array}$} & $<60$ & 909 & 92.8 \\
\hline & $\geq 60$ & 70 & 7.2 \\
\hline \multirow{2}{*}{$\begin{array}{l}\text { Apgar score } \\
1 \mathrm{~min}\end{array}$} & $\geq 7$ & 774 & 79.1 \\
\hline & $<7$ & 205 & 20.9 \\
\hline \multirow{2}{*}{$\begin{array}{l}\text { Apgar score } \\
5 \mathrm{~min}\end{array}$} & $\geq 7$ & 807 & 82.4 \\
\hline & $<7$ & 172 & 17.6 \\
\hline \multirow{4}{*}{$\begin{array}{l}\text { Neonatal } \\
\text { complication; }\end{array}$} & \begin{tabular}{|l|} 
Respiratory \\
distress
\end{tabular} & 90 & 9.2 \\
\hline & \begin{tabular}{|l|} 
Neonatal \\
sepsis
\end{tabular} & 22 & 2.3 \\
\hline & \begin{tabular}{|l|}
$\begin{array}{l}\text { Neonatal } \\
\text { jaundice }\end{array}$ \\
\end{tabular} & 19 & 1.9 \\
\hline & $\begin{array}{l}\text { Meconium } \\
\text { aspiration }\end{array}$ & 60 & 6.1 \\
\hline \multicolumn{2}{|c|}{ NICU Admission } & $\begin{array}{c}\text { Mean } 6 \\
\text { hours }\end{array}$ & $\begin{array}{c}\text { Minimum } \\
3 \text { hours } \\
\text { Maximum } \\
12 \text { day }\end{array}$ \\
\hline \multicolumn{2}{|c|}{ Blood gases done for; } & 172 & 17.6 \\
\hline \multicolumn{2}{|c|}{ Neonatal death; } & 10 & 1 \\
\hline
\end{tabular}

\section{DISCUSSION}

During the past few decades, the cesarean section delivery rate has been increasing almost everywhere, and the Arab region is no exception. Although the exact risk of death from CS is decreasing in the western world, data extrapolated from confidential enquiries in the United Kingdom estimated the risk of maternal death from CS is still 3 times greater than that with vaginal delivery ${ }^{(\mathbf{1 4})}$.

According to Egyptian demographic and health surveys (EDHS), hospital-based cesarean rates show a rising trends from a low of $13.9 \%$ in 1988 , to $15.3 \%$ in 1992 , to $18.5 \%$ in 1995 to reach $20.9 \%$ in 2000 , to a high of $26.2 \%$ in $2003^{(\mathbf{1 3})}$.

The 2008 EDHS shows that more than onequarter of deliveries in the five-year period before the survey were by cesarean section and about $37 \%$ of urban births were cesarean deliveries compared to $22 \%$ of rural births ${ }^{(\mathbf{1 5})}$. According to EDHS, the cesarean section rate increased to $27.6 \%$ in $2008^{(16)}$.

This study at Benha Educational Hospital showed that cesarean sections were done for women of different ages. The most of the females delivered by cesarean section were between 20-30years (53.3\%). T

hese results agreed with Chanthasenanont et al. (17) results; who found that the rate within this age group was $82.17 \%$, and Menacker and Hamilton ${ }^{(\mathbf{1 8})}$ who found that rates of cesarean delivery typically rise with increasing maternal age as the rate for mothers aged 4054 years in 2007 was more than twice the rate for mothers under the age of 20 (48\% and $23 \%$, respectively).

Menacker and Hamilton explained that the risk for cesarean delivery was increased secondary to medical complications such as diabetes and preeclampsia. Our study showed that the mean age of the mother was $28.8 \pm 4.9$, while the mean age recorded by Chanthasenanont et al. ${ }^{(17)}$ was $28.89+5.59$.

This study showed that the most common indication of cesarean section was previous cesarean section (61.6\%) followed by relative indication was (27.6\%) then absolute indication which is cephalo-pelvic disproportion (CPD) was (10.8\%); this may be due to decrease or even no practice of VBAC (vaginal delivery after cesarean section) and decrease of trial of vaginal delivery for breech presentation. According to an audit conducted in south Africa by Naidoo et al. ${ }^{\left({ }^{(9)}\right)}$ who found that, the main indications for CS were previous CS $(51 / 209 ; 24.4 \%)$ emergency CS for CPD $(17 / 209 ; 8.13 \%)$ and elective CS for previous CS x 2 $(13 / 209,6.2 \%)$.

In our study NICU admission occurred due to neonatal complication as respiratory distress (9.2\%), meconium aspiration $(6.1 \%)$, neonatal sepsis $(2.3 \%)$ and neonatal jaundice (1.9\%).

These results were not in agreement with Katke et al. ${ }^{(20)}$ who found that NICU occurred in $20.8 \%$, and the most common cause of NICU admission was low birth weight (LBW) (30.6\%) followed by respiratory distress $(27.3 \%)$.

The American College of Obstetricians and Gynecologists in 2013 recommended that vaginal delivery in the absence of fetal and maternal indications is much safer for the fetus. The risk of respiratory morbidity, including transient tachypnea of the newborn, respiratory distress syndrome, and persistent pulmonary hypertension, is higher for elective cesarean delivery compared with vaginal delivery when delivery is earlier than 39-40 weeks of gestation ${ }^{(\mathbf{2 1}, \mathbf{2 2})}$. 


\section{REFERRENCES}

1. Roberts CL and Nippita TA (2015): International caesarean section rates: the rising tide. Lancet Glob Health, 3(5):241-242.

2. Belizan JM, Farnot U, Carroli G et al. (1999): Antenatal care in developing countries. paediatr perinat Epidemiol., 12(12):1-3.

3. Tollånes MC, Melve KK, Irgens LM, Skjaerven $\mathbf{R}$ (2007): Reduced fertility after cesarean delivery: a maternal choice. Obstetrics \& Gynecology, 110(6):12561263.

4. Leone T, Padmadas SS, Matthews Z (2008): Community factors affecting rising caesarean section rates in developing countries: an analysis of six countries. Social Science \& Medicine, 67(8):1236-1246.

5. MacDorman MF, Menacker F and Declereq E (2008): Cesarean birth in the united states: Epidemiology, trends and outcomes. Clin perinatal, 35(2):293-307.

6. Menacker F, Declereq E, MacDorman MF (2006): Cesarean delivery: backgroud trends, and epidemiology. Semin Perinatol., 30: 235-2413.

7. Henderson J, McCandlish R, Kumiega L et al. (2001): Systematic review of economic aspects of alternative mode of delivery. BJOG., 108: 149-157.

8. Gibbons L, Belizán JM, Lauer JA, Betrán AP, Merialdi M, Althabe F (2010): The global numbers and costs of additionally needed and unnecessary caesarean sections performed per year: overuse as a barrier to universal coverage. World health report, 30:1-31.

9. Ecker JL and Frigoletto FD (2007): Cesarean delivery and the risk benefit calculus. N Engl J Med., 356:885-888.

10. Landon MB, Hauth JC, Leveno KJ et al. (2004): Maternal and perinatal outcome associated with atrial of labor after prior cesarean delivery. N Engl Med., 351:25812589.

11. Yang Q, Wen SW, Oppenhrimer L et al. (2007): Association of caesarean delivery for firest birth with placenta previa and placenta abruption in second pregnancy. BLOG., 114:609-13.
12. Villar J, Valladares E, WoJdyia D et al. (2006): Caesarean delivery rates and pregnancy outcomes: the 2005 who global survey on maternal and perinatal health in latin America, Lancet, 367:1819-29

13. KhawaJa $M$, Tamer $K$ and Rozzet $J$ (2004): Determinants of cesarean section in Egypt: evidence from the demographic and health survey. Health policy, 69: 273281.

14. Hall HM and Bewley S (1999): Maternal mortality and mode of delivery. Lancet, 354:776.

15. El-Zanaty F (2009): Egypt Demographic and Health Survey breastfeeding. J Am Diet Assoc., 109(11):1926-42.

16. Egypt Demographic and Health Survey (2009): Cairo Egypt: Ministry of Health and Population, National Population Council, El-Zanaty \& Associates, and ORC Macro.

http://papers.ssrn.com/sol3/papers.cfm?abstract_id=16611 96.

17. Chanthasenanont $A$, Nanthakomon $T$, Kamudhamas $A$ (2007): Indications for cesarean at Thammasat University Hospital. J Med Assoc Thai., 90(9): 1733-7.

18. Menacker $\mathbf{F}$ and Hamilton BE (2010): Recent trends in caesarian delivery in the united states. U.S. centers for disease control and prevention. http://www.cdc.gov/nchs/data/data brief/ db35. pdf.

19. Naidoo $\mathbf{N}$, Moodley $\mathbf{J}$ (2009): Rising rates of Caesarean sections: an audit of Caesarean sections in a specialist private practice. South African Family Practice, 51:3.

20. Katke RD, Zarariya AN, Desai PV (2014): LSCS audit in a tertiary care center in Mumbai: to study indications and risk factors in LSCS and it's effect on early peri-natal morbidity and mortality rate. Int $\mathrm{J}$ Reprod Contracept Obstet Gynecol., 3:963-8.

21. Morrison JJ, Rennie JM, Milton PJ (1995): Neonatal respiratory morbidity and mode of delivery at term: influence of timing of elective caesarean section. $\mathrm{Br} \mathrm{J}$ Obstet Gynaecol., 102:101-6.

22. Zonardo V, Simbi AK, Franzoi M et al. (2004): Neonatal respiratory morbidity risk and mode of delivery at term: influence of timing of elective caesarean delivery. Acta Paediatr., 93:643-7. 